\title{
Impairments and Activity Limitations in Subjects With Chronic Upper-Limb Complex Regional Pain Syndrome Type I
}

\author{
Fabiënne C. Schasfoort, PhD, PT, Johannes B. Bussmann, PhD, PT, Henk J. Stam, PhD, MD
}

ABSTRACT. Schasfoort FC, Bussmann JB, Stam HJ. Impairments and activity limitations in subjects with chronic upper-limb complex regional pain syndrome type I. Arch Phys Med Rehabil 2004;85:557-66.

Objective: To determine the degree of impairments and activity limitations and their interrelationship in complex regional pain syndrome type I (CRPS type I).

Design: Cross-sectional study interrelating impairments and objectively measured activity limitations.

Setting: Ambulatory and home environment.

Participants: Thirty nonacute upper-limb CRPS type I subjects.

Interventions: Not applicable.

Main Outcome Measures: Sensory, motor, and autonomic impairments, as well as activity-limitation outcome measures. The latter were objectively measured with a novel upper-limb activity monitor (based on ambulatory accelerometry).

Results: All subjects were impaired to some degree but with a large variability with respect to magnitude. Regarding activity limitations, the involved upper limb was clearly less active (lower intensity and percentage of activity) than the noninvolved side. Impaired active range of motion (adjusted $R^{2}$ range, $18 \%-39 \%$ ) and grip strength (adjusted $R^{2}$ range, $12 \%-$ $45 \%$ ) were the most important factors explaining variance in activity limitations.

Conclusions: All subjects were still impaired nearly 3 years after the causative event. The involved upper limb was also clearly less active than the noninvolved side, especially when the subjects were sitting and when the dominant side was involved. The more impairments a subject had, especially motor impairments, the more activity limitations were present.

Key Words: Complex regional pain syndromes; Limitation on activity, chronic; Rehabilitation; Upper extremity.

(C) 2004 by the American Congress of Rehabilitation Medicine and the American Academy of Physical Medicine and Rehabilitation

COMPLEX REGIONAL PAIN syndrome type I (CRPS type I) (also known as reflex sympathetic dystrophy) is a poorly understood and variously defined symptom complex. ${ }^{1-9}$ When CRPS type I occurs, it usually follows surgery or trauma, and it is generally expressed in the extremities. Its course shows large variability, which makes diagnosis and interpreta-

From the Department of Rehabilitation Medicine, Erasmus MC, University Medical Center, Rotterdam, the Netherlands.

No commercial party having a direct financial interest in the results of the research supporting this article has or will confer a benefit upon the author(s) or upon any organization with which the author(s) is/are associated.

Correspondence to Fabiënne C. Schasfoort, PhD, PT, Dept of Rehabilitation Medicine, Rm Ee 1626 B, Erasmus MC, University Medical Center, PO Box 1738, 3000 DR Rotterdam, The Netherlands, e-mail: f.schasfoort@erasmusmc.nl. Reprints are not available from the author.

0003-9993/04/8504-8153\$30.00/0

doi:10.1016/j.apmr.2003.06.026 tion of clinical findings and research data difficult. Uncertainty surrounding the disorder is also reflected by the wide variety of treatments and, consequently, the numerous measures used to determine treatment outcome. ${ }^{9-12}$

Sensory, autonomic, trophic, and motor impairments may be found in CRPS type I. ${ }^{10,13,14}$ Furthermore, activity limitations during normal daily life, including occupation ${ }^{8,15-24}$ and participation problems such as social functioning and role fulfillment, have been reported. ${ }^{25,26}$ These studies show that CRPS type I encompasses impairments, activity limitations, and participation problems as described in the International Classification of Functioning 27-30 (ICF). However, most outcome measures used in CRPS type I research concentrate on impairments. ${ }^{10,31}$ To date, there has been a lack of appropriate instruments to objectively determine activity limitations of subjects with upper-limb CRPS type I. ${ }^{10}$ The few instruments used in CRPS type I research to determine activity limitations have been retrospective scales and questionnaires. From a rehabilitation viewpoint, it is important to analyze the relation between impairments and activity limitations in order to address such questions as: Does an impairment always lead to activity limitations? Should treatment or prevention focus on impairment or activity limitations ? $^{16}$ and Which impairment mainly affects activities? However, only 2 studies $^{16,25}$ have investigated the relation between impairment and activity limitations in CRPS type I. In both of these studies, ${ }^{16,25}$ scales and questionnaires were used to determine activity limitations: a visual analog scale for perceived limitations in activities of daily living (VAS-ADLs) and the Groningen Activity Restrictions Scale (GARS) for activity limitations.

The present study used an upper-limb activity monitor (ULAM), which was developed to objectively measure and quantify upper-limb activity while a subject is functioning during normal daily life. ${ }^{32}$ The ULAM has proven its ability to noninvasively detect limitations in upper-limb activity in chronic upper-limb CRPS type I subjects. ${ }^{33}$ The advantages of the ULAM over scales and questionnaires are, for example, that it is more extensive than VAS-ADLs and, more important, provides objective outcome measures for activity limitations that allows quantification of what subjects actually do in normal daily life and not what they report they are capable of.

Our aim was to analyze the relation between impairments and objectively measured activity limitations in upper-limb CRPS type I subjects. This study is the first to determine how impairments and objectively measured activity limitations are interrelated in upper-limb CRPS type I. The research questions were: (1) What is the degree of impairments and activity limitations? (2) What is the relation between impairments and activity limitations? (3) Which impairment(s) mainly explain(s) activity limitations? and (4) Do other variables influence the relation between impairment and activity limitations? 


\section{METHODS}

\section{Participants}

Thirty subjects with CRPS type I in 1 upper limb volunteered for this cross-sectional study. In 15 subjects, the dominant side was involved and in the other 15 the nondominant side. There was only 1 male subject; the average age \pm standard deviation (SD) was 55.1 \pm 14.9 years (range, $20-81 \mathrm{y}$ ). Mean duration of CRPS type I between onset and measurements was 33 months. Inclusion criteria were presence of Veldman's criteria $^{13}$ at diagnosis and ongoing CRPS type I-related complaints at enrollment into the study. The criteria of Veldman were (1) 4 or 5 of the following: unexplained diffuse pain, different skin color relative to other side, diffuse edema, different skin temperature relative to other side, and limited active range of motion (AROM); (2) occurrence or increase of signs and symptoms after use; and (3) presence of signs and symptoms in an area larger than was initially involved, including the area distal to primary injury. These criteria do not substantially differ from the International Association for the Study of Pain (IASP) criteria. ${ }^{3,34}$ Subjects were excluded if comorbidities affecting upper-limb usage or general mobility were present. Informed consent was obtained from all subjects and the study was approved by the Medical Ethics Committee of Erasmus MC.

\section{Impairment Measures}

The Impairment Sum Score ${ }^{11}$ (ISS), a validated set of 5 items (temperature, VAS pain, McGill Pain Questionnaire [MPQ], AROM, volume) developed specifically for upper-limb CRPS type I, was used to determine the degree of impairment. However, because the ISS, as most other sum scores, $4,11,16,35-37$ is based on diagnostic criteria, it was considered incomplete to study the present population. Because it has recently been recognized that motor impairments are not only prominent in chronic CRPS type I, ${ }^{8,13,18,19,38-42}$ but are also a distinct component to be incorporated in the IASP criteria for it, ${ }^{4}$ we chose loss of grip strength as an additional item.

ISS temperature. An infrared thermometer ${ }^{\mathrm{a}}$ was used (measurement range, $0^{\circ}-42.2^{\circ} \mathrm{C}$; accuracy, $\pm 0.2^{\circ} \mathrm{C}$ ). Temperature can be reliably measured dorsally perpendicular to the middle of the hand after 10 to 15 minutes acclimatization. ${ }^{43}$ Normal temperature difference between both hands was set at $0.3^{\circ} \mathrm{C}$ or less. ${ }^{11}$

ISS-VAS. Pain resulting from effort was measured with a VAS indicated on a $100-\mathrm{mm}$ horizontal line. This is a reliable and valid instrument to measure intensity of pain. ${ }^{44}$

$I S S-M P Q$. The MPQ is often used in CRPS type I research. ${ }^{45-47}$ We used the total number of words chosen by the subject from the list of sensory, affective, and evaluative pain words from the reliable ${ }^{48}$ Dutch language version (MPQ-DLV) to assess pain during the previous week.

ISS-AROM. Maximum AROM within pain threshold was measured. We determined percentages of normal AROM (involved vs noninvolved side) for the wrist (dorsal and palmar flexion) and metacarpophalangeal and proximal interphalangeal (flexion, extension) of the 2 most impaired digits. Each joint movement was measured 3 times and averaged. ${ }^{11,49,50}$

ISS volume. Volumetric measurements of the hands were taken with a volumeter, ${ }^{b}$ which determines fluid overflow. The difference in volume between both hands was considered in relation to the volume of the unimpaired hand. A difference in volume up to $3.5 \%$ was considered normal. ${ }^{11}$

Strength. A portable hand-held dynamometer ${ }^{c}$ was used, which allows quantification and, if performed in a standardized manner, reproducible and reliable ${ }^{51}$ determination of grip strength. Only 4-point grip strength was measured because several forms of grip strength were well correlated in CRPS type I subjects. ${ }^{25}$ Subjects were instructed to squeeze as hard as possible with hands in the lumbrical grip (thumb at bottom and digits II-IV on top of the device). Strength was measured 3 times after 1 practice, and the average was calculated for both the involved and noninvolved side. Oerlemans et al ${ }^{11}$ converted the ISS impairment items to a range of 1 to 10 (based on intraindividual comparisons for AROM, volume, and temperature of both hands). A score of 1 was interpreted as absence of that impairment. To make grip strength comparable with ISS in the present study we also ascribed intraindividual comparisons for grip strength on a 1 to 10 scale as follows: 1 , strength of the involved side greater than $90 \%$ of the noninvolved side, 10 , strength of the involved side between $0 \%$ and $10 \%$; intermediate strength differences were ascribed scores between 2 and 9. This score was added to the 5 ISSs to create the Total Impairment Score (TIS), which ranged from 6 to 60, with higher scores indicating more severe impairment.

\section{Activity Limitation Measures}

The ULAM is an extended version of the classic activity monitor, which was developed and validated in our department. ${ }^{52-57}$ The activity monitor measures mobility-related activities such as lying, sitting, standing, walking, cycling, and general movement. This portable device enables detailed, longterm ambulatory measurement of what subjects actually do during normal daily life and can therefore be used to determine activity level and, if present, activity limitations. The ULAM was developed to determine activity limitations of subjects with disorders related to the upper limbs. It enables one to determine whether the upper limbs are active when a subject is performing one of the mobility-related activities. ${ }^{32}$ The combination of mobility-related activities and upper-limb activity allows one to obtain more specific information than with other techniques, such as a wrist actigraph or actometer. ${ }^{58-62}$

Uniaxial piezoresistive acceleration sensors, ${ }^{\mathrm{d}}$ attached to the subject's thighs (sensitive direction in sagittal plane), trunk (sensitive direction in sagittal and longitudinal plane), and forearms (sensitive direction in sagittal plane being in the anatomic position) were connected to a small recorder ${ }^{\mathrm{e}}$ that was worn around the waist (fig 1). The raw acceleration signals are expressed in $g\left(9.81 \mathrm{~ms}^{-2}\right)$ and are a combination of 2 components: gravitational acceleration and accelerations due to activity. ${ }^{57,63}$ The raw data were stored digitally on a 40 megabyte flash card ${ }^{\mathrm{f}}$ with a sample frequency of $32 \mathrm{~Hz}$ and downloaded onto a personal computer for subsequent analysis.

Automatic detection of mobility-related activities and upperlimb activity was done by kinematic analysis based on signal processing and inferencing language routines, yielding $\mathrm{C}$ code. ${ }^{64}$ For detection, 3 feature signals (angular, motility, frequency) were derived from each raw acceleration signal (time resolution, 1s). The subsequent steps of analysis have been described previously. ${ }^{53-55,57,65,66}$ To detect upper-limb activity, the ULAM uses the motility feature (finite impulse response filter, $0.3-16 \mathrm{~Hz}$, envelope of the alternating current component of the acceleration signal), which is the variability around the mean in the raw acceleration signal expressed in $g\left(9.81 \mathrm{~ms}^{-1}\right)$. This variability can be considered as a measure for the intensity of upper-limb activity: the more intensely active, the higher the motility value. For a more technical description of the detection method, see other studies. ${ }^{32,57}$ Basing our decisions on previous research, ${ }^{33,56}$ we used the following outcome measures to assess subjects' limitations. 


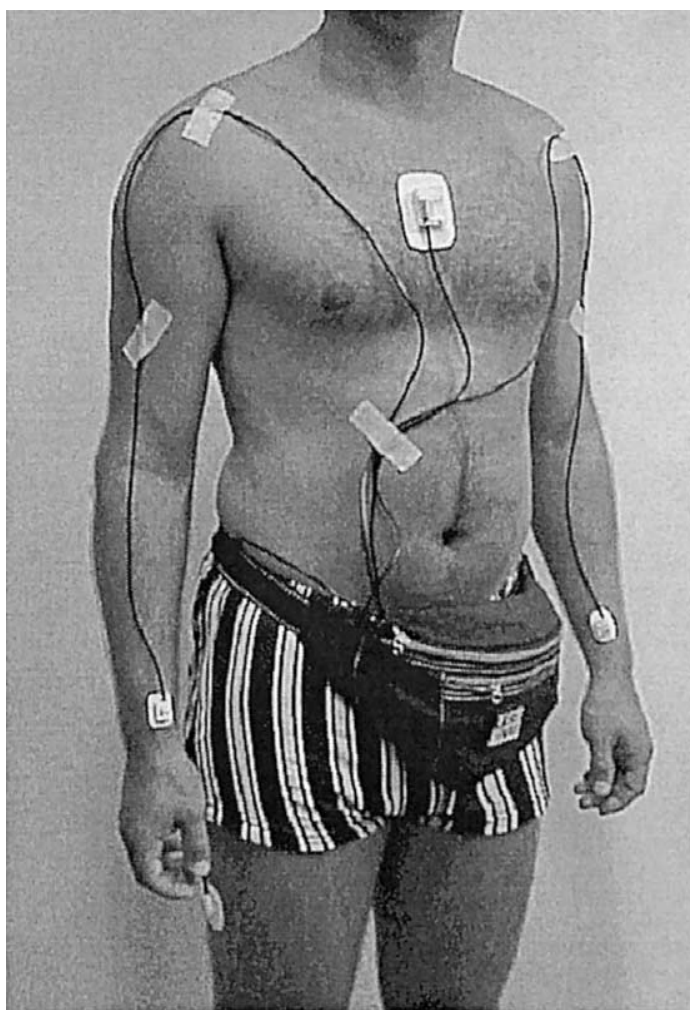

Fig 1. A subject wearing the ULAM device.

Mean intensity of upper-limb activity of the involved side during sitting and standing. The mean intensity of upperlimb activity of the involved side was expressed in mean (scaled) motility values during the time the involved upper limb was active while the subjects were sitting and standing. The lower the mean intensity, the more limited the activity.

Percentage of upper-limb activity of the involved side during sitting and standing. The percentage of upper-limb activity of the involved side was expressed as the percentage of the time that the involved upper limb was active (ie, exceeding a threshold in the motility value) while the subjects were sitting and standing. The lower the percentage of upper-limb activity, the more limited the activity.

Proportion of activity between upper limbs during sitting and standing. The proportion of activity of 1 upper limb relative to the other was expressed as a ratio: the percentage of activity of the nondominant side relative to that of the dominant side. These ratios were normalized according to a reference value derived from 10 healthy subjects in an earlier study. ${ }^{33}$ For subjects with dominant side involvement, a ratio higher than 1 was associated with activity limitations. For subjects with nondominant side involvement, a ratio lower than 1 was associated with activity limitations. The higher or lower these respective ratios, the more limited the activity.

Percentage of dynamic mobility-related activities. The percentage of the measurement period during which the subject performed dynamic mobility-related activities (ie, walking, cycling, general noncyclic activity) was also used as a measure of activity limitation. The lower the percentage of time spent in these activities, the more limited the subject was in activity.

\section{Other Variables}

Some demographic variables, such as age, gender, marital status, and employment status, may influence the relation between impairments and activity. Duration of CRPS type I, time between onset and diagnosis, and whether the subject was receiving therapy or medication may also influence this relationship. Involvement of the dominant or nondominant side should also be taken into account because the interrelation between impairment and activity may differ depending on whether the dominant side is involved.

\section{Protocol}

To reduce interference with normal daily life, the ULAM was fitted at home and worn for 24 hours. Subjects were instructed to continue their ordinary activities, except for swimming, bathing, or showering. To avoid bias, the exact technique and output parameters were not explained: the subjects were just told that the sensors detect movement of body parts to which they were attached. After 24 hours, the device was removed, subject characteristics and activities performed were noted, and the 6 impairments were measured. At this stage, the subject was given complete information about what the ULAM measures: a 24-hour activity pattern of whether the upper limbs are active or not, plus which mobility-related activity was performed. All subjects agreed with this protocol. Measurements on day 2 took approximately 1.5 hours; the order of measurement was the same for each subject, with grip strength being measured last to avoid provoking physical complaints (eg, pain) or increasing temperature.

\section{Statistics}

Nonparametric statistical methods were used. We used Spearman rank coefficients to describe correlations between outcome measures and other variables, the Wilcoxon signedrank test to determine whether outcome measures differed between involved and noninvolved sides, and the Mann-Whitney $U$ test to determine whether activity-limitation outcome measures differed between subjects with dominant and nondominant side involvement.

After we confirmed that linear regression could analyze the relation between impairment and activity limitations, we performed simple linear regression for each dependent variable, with impairment outcome measures as independent variables. Statistically significant $(P \leq .05)$ impairments that explained $10 \%$ or more of the variance in the simple models were included in the multiple models. Separate regression models were made for the 2 subgroups for the proportion of activity between both upper limbs during sitting and standing. We used SPSS, version $10.0,{ }^{\mathrm{g}}$ for Windows, for data analysis.

\section{RESULTS}

\section{Participant Characteristics}

Most subjects were between the age of 40 and 70 years (table 1). Only 1 man participated. Overall, the main precipitating event was 1 or more fracture(s). Most subjects had CRPS type I for more than 1 year (mean, 32.8 $\pm 31.3 \mathrm{mo}$; range, $4-143 \mathrm{mo}$ ). In about one third of the subjects, the time between onset and diagnosis was more than 2 months (range, 3-33mo).

\section{Impairments}

Impairment scores ranged considerably (table 2): nearly all possible values were present for each outcome measure. Median scores for ISS-AROM, strength, ISS-MPQ, and ISS-VAS were higher than the median scores for ISS volume and ISS 
Table 1: Subject Characteristics

\begin{tabular}{|c|c|c|}
\hline Characteristic & $\mathrm{n}$ & $\%$ \\
\hline \multicolumn{3}{|l|}{ Age (y) } \\
\hline 20-30 & 2 & 6.7 \\
\hline $31-40$ & 3 & 10.0 \\
\hline $41-50$ & 5 & 16.7 \\
\hline $51-60$ & 10 & 33.3 \\
\hline $61-70$ & 5 & 16.7 \\
\hline $71-80$ & 3 & 10.0 \\
\hline $80+$ & 2 & 6.7 \\
\hline \multicolumn{3}{|l|}{ Gender } \\
\hline Men & 1 & 3.3 \\
\hline Women & 29 & 96.7 \\
\hline \multicolumn{3}{|l|}{ Causative event } \\
\hline Fracture & 15 & 50.0 \\
\hline Other & 11 & 36.7 \\
\hline Idiopathic & 4 & 13.3 \\
\hline \multicolumn{3}{|l|}{ Time since onset (mo) } \\
\hline $0-3$ & 0 & 0 \\
\hline $3-12$ & 9 & 30 \\
\hline $12+$ & 21 & 70 \\
\hline \multicolumn{3}{|c|}{ Time between onset and diagnosis } \\
\hline$\leq 2 \mathrm{mo}$ & 19 & 63.3 \\
\hline$>2 \mathrm{mo}$ & 11 & 36.7 \\
\hline \multicolumn{3}{|l|}{ Employment } \\
\hline Yes, part-time & 7 & 23.3 \\
\hline No, retired & 4 & 13.3 \\
\hline No, workers' comp & 10 & 33.3 \\
\hline No, housewife & 9 & 30.0 \\
\hline
\end{tabular}

Abbreviation: comp, compensation

temperature. The only impairment that was present to some degree in all subjects was impaired AROM. No subject was completely unimpaired, as indicated by the minimum TIS of 13. TISs were not related to any of the other variables such as age or other demographic variables, duration of CRPS type I, time between onset and diagnosis, and having therapy or not. No significant differences existed between those with dominant side and those with nondominant side involvement with respect to impairment outcome measures or any other variables. The ISS-VAS values did not correlate well with ISS-MPQ $(r=.21)$. Momentary pain (measured by VAS) ranged from 0 to $70 \mathrm{~mm}$ (median, 13mm) and correlated significantly with ISS-VAS pain resulting from effort $(r=.71, P=.000)$. Momentary pain was significantly less than pain resulting from effort $(P=.000)$.

\section{Activity Limitations}

The mean intensity and percentage of upper-limb activity of the involved side were significantly less than the noninvolved side, during both sitting and standing (table 3, top). The percentage of dynamic mobility-related activities did not differ significantly between subjects with dominant side involvement and those with nondominant side involvement (table 3, bottom); also, between these 2 subgroups no significant differences existed for the mean intensity and percentage of upperlimb activity of the involved sides. Compared with the mean activity intensity of the dominant $(4.04 \mathrm{~g})$ and nondominant (3.66g) side of 10 healthy subjects during sitting, ${ }^{33}$ in these CRPS type I subjects the activity of the involved side was low $(3.10 \mathrm{~g})$. This finding was also true for the percentage of upperlimb activity during sitting (healthy subjects: dominant side, $37.5 \%$; nondominant side, $35.6 \%$ ).
Table 4 gives on the proportion of activity between both upper limbs during sitting and standing separately for both subgroups. Not all subjects were limited with respect to these outcome measures: most interquartile ranges included the reference value. Only 7 subjects $(23 \%)$ were classified as limited. Subsequent analysis revealed that, for the subjects with dominant side involvement, limitations in the proportion of upperlimb activity during sitting were due to a lower percentage of upper-limb activity of that side; and that, during standing, the activity of the noninvolved (nondominant) upper limb was increased. There was no such increase or decrease of percentage of upper-limb activity in persons with nondominant side involvement.

\section{Relation Between Impairments and Activity Limitations}

The TIS, ISS-AROM, and strength values were significant in each simple model for the mean intensity and percentage of activity of the involved upper limb during sitting and standing (table 5). Further, ISS-VAS and ISS temperature were significant in both the simple models during sitting. Because age was considered a potential confounder for activity (ie, the older, the less active), it was always included in the multiple models. In the multiple models, AROM $(P=.009)$ and age $(P=.001)$ were significant contributors to the percentage of upper-limb activity during standing. The variability in upper-limb outcome measures explained by impairments and age ranged from $24 \%$ to $52 \%$. Because the percentage of activities related to dynamic mobility (avg, 11.3\%) performed by CRPS type I subjects did not differ from earlier findings in healthy subjects, ${ }^{65,66}$ indicating that the CRPS type I subjects were not limited with respect to mobility, we decided not to make regression models for this ULAM outcome measure.

Regarding the proportion of activity between both upper limbs during sitting and standing, ISS-AROM and the TIS were significant in 3 of the 4 simple regression models made for both subgroups (table 6). Strength was significant in each simple model. The multiple regression models for the 2 subgroups explained variances ranging from $34 \%$ to $57 \%$.

\section{Other Variables}

The relative temperature score (the degree to which the involved side is colder or warmer than the noninvolved side) correlated significantly $(r=.38, P=.037)$ with the percentage of upper-limb activity: the colder the hand, the lower the percentage of activity. Also, the involved side of subjects having CRPS type I for more than 12 months was significantly $(P=.02)$ colder than that in subjects whose CRPS type I was of shorter duration. Duration of CRPS type I, time between onset and diagnosis, employment status, marital status, and level of education were not related to the upper-limb activity outcome measures.

Table 2: Impairment Outcome Measures

\begin{tabular}{lc}
\hline Impairment (possible range) & Median (Range) \\
\hline ISS-VAS (1-10) & $5(1-10)$ \\
ISS-MPO (1-10) & $6(1-10)$ \\
ISS-AROM (1-10) & $7(3-10)$ \\
ISS volume (1-10) & $2(1-10)$ \\
ISS temperature (1-10) & $3(1-10)$ \\
Strength (1-10) & $6(1-10)$ \\
TIS (6-60) & $31.5(13-52)$ \\
\hline
\end{tabular}


Table 3: Activity Limitation, Intrasubject and Intergroup Comparisons

\begin{tabular}{|c|c|c|c|}
\hline Activity Limitations & Mean \pm SD & Mean \pm SD & $P$ Value \\
\hline Within-Subject Comparison & Involved Side $(\mathrm{N}=30)$ & Noninvolved Side $(\mathrm{N}=30)$ & Wilcoxon \\
\hline Intensity sitting $(g \times 100)$ & $3.10 \pm 0.99$ & $4.17 \pm 1.66$ & .001 \\
\hline Intensity standing $(g \times 100)$ & $9.96 \pm 3.16$ & $12.88 \pm 3.38$ & .001 \\
\hline Percentage sitting (\%) & $29.20 \pm 8.54$ & $34.64 \pm 9.96$ & .008 \\
\hline Percentage standing (\%) & $72.96 \pm 10.85$ & $78.66 \pm 10.06$ & .002 \\
\hline Between-Group Comparison & $\begin{array}{l}\text { Dominant } \\
\text { Involvement }(n=15)\end{array}$ & $\begin{array}{c}\text { Nondominant } \\
\text { Involvement }(n=15)\end{array}$ & Mann-Whitney \\
\hline $\begin{array}{l}\text { Percentage of dynamic mobility activities (\%) } \\
\text { Involved side }\end{array}$ & \multicolumn{2}{|c|}{ Involved side } & .604 \\
\hline Intensity sitting $(g \times 100)$ & $2.98 \pm 1.08$ & $3.21 \pm 0.91$ & .455 \\
\hline Intensity standing $(g \times 100)$ & $10.82 \pm 3.72$ & $9.11 \pm 2.30$ & .254 \\
\hline \multicolumn{4}{|l|}{ Involved side } \\
\hline Percentage sitting (\%) & $27.76 \pm 9.56$ & $30.63 \pm 7.42$ & .237 \\
\hline Percentage standing (\%) & $72.69 \pm 10.66$ & $73.23 \pm 11.4$ & .820 \\
\hline
\end{tabular}

\section{DISCUSSION}

\section{Impairments}

The large intersubject variability in magnitude of impairments that we found is in accordance with other studies. ${ }^{11,13}$ Our mutual impairment correlations did not differ from the findings of Oerlemans et $\mathrm{al}^{11}$ in more acute CRPS type I, with the exception of the present significant correlations between VAS-AROM $(r=.50)$ and VAS volume $(r=.37)$. None of the impairments was related to duration of CRPS type I. In our chronic population, impaired strength, AROM, and pain were most prominent, which supports earlier findings that motor impairments become more important as the complicated syndrome becomes chronic. ${ }^{8,13,18,19,38-42}$

The AROM was most impaired in our cohort, but it did not differ between subjects with multiple fractures or another causative event. In contrast to other motor impairments, because $\mathrm{AROM}$ and strength are relatively constant throughout the day, they were considered more suitable as outcome measures. The problem remains, however, that although rigidly standardized in every aspect, AROM and grip strength measurements may be subject to considerable systematic and random variation. ${ }^{49,51}$ We anticipated this problem and sought to mitigate it by determining average scores of 3 movements per joint. Geertzen et $\mathrm{al}^{49}$ also reported AROM differences between the involved and noninvolved side in shoulder, elbow, and wrist but did not consider these differences clinically relevant because AROM was within the range needed for normal daily life. Because small reductions in mobility-especially in the hand-are thought to predominantly affect fine motor skills, ${ }^{11}$ we consid-

Table 4: Proportion of Upper-Limb Activity, Nondominant Versus Dominant Side Involvement

\begin{tabular}{lcc}
\hline \multicolumn{1}{c}{ Side of Involvement } & $\begin{array}{c}\text { Sitting } \\
\text { Median (IOR) }\end{array}$ & $\begin{array}{c}\text { Standing } \\
\text { Median (IQR) }\end{array}$ \\
\hline Dominant $(\mathrm{n}=15)$ & $1.20(0.85-1.61)$ & $1.13(1.05-1.19)$ \\
Nondominant $(\mathrm{n}=15)$ & $0.88(0.74-0.98)$ & $0.98(0.96-1.01)$
\end{tabular}

NOTE. Median scores interquartile range (IQR) for the normalized ratios for the proportion of activity between both upper limbs during sitting and standing for both subgroups. For dominant side involvement, a ratio above 1 was associated with activity limitations. For nondominant side involvement, a ratio below 1 was associated with activity limitations. The higher or lower these respective ratios, the more limited a subject was. ered AROM of wrist and fingers a more important outcome measure than AROM of shoulder and elbow. We did not find other motor impairments such as tremors, spasms, or dystonia during the measurements on the second day. These impairments have been reported in small patient groups with more generalized and severe CRPS type $\mathrm{I}^{8,13,40-42,67}$ but are not common. ${ }^{16,41,42,68,69}$ Also, their underlying mechanism is unclear. ${ }^{19,40,41,70}$

Temperature and volume appeared least impaired. Regarding skin temperature, Oerlemans ${ }^{11}$ pointed out that unequivocal measurement is difficult because temperature may change with time in CRPS type $\mathrm{I}^{11,13,71}$ and may be higher or lower than on the contralateral side. ${ }^{72,73}$ Moreover, objective and subjective temperature measurements do not always correspond in CRPS type I. $^{74}$ To partly overcome such validity problems, we differentiated between a warmer or colder involved side compared with the noninvolved side. The finding that the involved sides were significantly colder in CRPS type I of longer duration was in accordance with findings from advanced techniques measuring the vascular reflex response during a complete thermoregulatory cycle. ${ }^{75}$ No subject was in the acute phase $(<3 \mathrm{mo})$, so we cannot contribute to the discussion about subsequent stages in CRPS type I. ${ }^{13,68,75-80}$

The ISS-MPQ correlated poorly with other impairments both in our study and in that of Oerlemans. ${ }^{11}$ The MPQ assesses sensory, affective, and evaluative aspects of pain ${ }^{81}$ and, for this reason, measures more than impairment level. ${ }^{11}$ Our data were in accordance with the finding that chronic pain patients such as those with CRPS type I choose affective and, especially, evaluative aspects with greater frequency than acute patients. ${ }^{74,82}$ Sensory indicators tingling, stiff and nagging, affective indicator tiring, and evaluative indicators tolerable/bearable and annoying (MPQ-DLV) were indicated most often. The ISS-VAS correlated more strongly with the ISS-MPQ's affective and evaluative aspects than with its sensory aspects; although a VAS is intended to measure pain intensity, chronic CRPS type I subjects may indeed use it to reflect affective and evaluative aspects of pain. ${ }^{11,83}$ Because acute pain becomes chronic pain as the syndrome continues, the MPQ is important to monitor changes over time. Although not all CRPS type I patients have pain, ${ }^{8,13}$ it is too important an aspect to quantify using only a simple VAS. ${ }^{25}$ 
Table 5: Relation 1 Between Impairments and Activity Limitations

\begin{tabular}{|c|c|c|c|c|c|c|c|c|}
\hline \multirow[b]{2}{*}{ Impairment } & \multicolumn{2}{|c|}{ Intensity Sitting } & \multicolumn{2}{|c|}{ Intensity Standing } & \multicolumn{2}{|c|}{ Percentage Sitting } & \multicolumn{2}{|c|}{ Percentage Standing } \\
\hline & $\beta$ & Adj $R^{2}$ & $\beta$ & Adj $R^{2}$ & $\beta$ & Adj $R^{2}$ & $\beta$ & Adj $R^{2}$ \\
\hline \multicolumn{9}{|l|}{ Simple models } \\
\hline ISS-VAS & & $.12 *$ & & .00 & & $.12^{*}$ & & .00 \\
\hline ISS-MPO & & .00 & & .00 & & .00 & & .00 \\
\hline ISS-AROM & & $.24^{+}$ & & $.23^{\dagger}$ & & $.18^{\dagger}$ & & $.29^{\ddagger}$ \\
\hline ISS volume & & .04 & & .06 & & .07 & & .00 \\
\hline ISS temperature & & $.12 *$ & & .00 & & .04 & & .00 \\
\hline Strength & & $.34^{\ddagger}$ & & $.15^{*}$ & & $.31^{\ddagger}$ & & $.12 *$ \\
\hline TIS & & $.36^{\ddagger}$ & & $.14^{*}$ & & $.31^{\ddagger}$ & & $.14^{*}$ \\
\hline \multicolumn{9}{|l|}{ Multiple models } \\
\hline Age & .21 & & .22 & & .14 & & .50 & $\neq$ \\
\hline ISS-VAS & .03 & & - & & -.04 & & - & \\
\hline ISS-AROM & -.23 & & -.40 & & -.17 & & -.47 & + \\
\hline ISS temperature & -.31 & & - & & - & & - & \\
\hline Strength & -.35 & & -.12 & & -.41 & & -.03 & \\
\hline Total adjusted $R^{2}$ & & $.39^{\dagger}$ & & $.24^{*}$ & & $.27^{*}$ & & $.52^{\ddagger}$ \\
\hline
\end{tabular}

NOTE. Mean intensity and percentage of upper-limb activity during sitting and standing are dependent variables and impairment outcome measures are independent variables. For the simple models, the adjusted $R^{2}$ is shown. For the multiple models, the standardized $\beta$ regression coefficients and the total adjusted $R^{2}$ are shown for impairments that were significant in the simple regression models (and age). Negative values were not significant in the simple model and are therefore not included in the multiple model.

Abbreviation: Adj, adjusted.

${ }^{*} P \leq .05 ;{ }^{+} P \leq .01 ;{ }^{\ddagger} P \leq .001$.

\section{Activity Limitations}

Although our subjects with dominant side involvement were somewhat less active, in general, CRPS type I in 1 upper limb does not appear to limit general mobility. The involved side was, on average, significantly disused or spared or protected, during both sitting and standing. Unfortunately, it was not possible to detect to what degree disuse and/or sparing or protecting were responsible for this inactivity. ${ }^{32}$ Moreover, because upper-limb activity during standing in our CRPS type I group did not differ from healthy subjects, upper-limb activity during sitting seems to be the most important aspect to investigate when determining activity limitations resulting from an upper-limb disorder.
In the present study, the lack of significant differences for mean intensity and percentage of activity of the involved upper limb between both subgroups (see table 4) seems to indicate that both subgroups were equally limited; however, subjects with dominant-side involvement were more limited. With respect to intensity and percentage of upper-limb activity, equal absolute values of the dominant and nondominant involved sides are due to a relatively larger decrease in activity of the dominant involved side than of the nondominant involved side; in healthy upper-limb activity, the dominant side is more active than the nondominant side. ${ }^{84,85}$ Because our 2 subgroups were similar with respect to duration of CRPS type I, impairment scores, and other relevant variables, one may conclude that the

Table 6: Relation 2 Between Impairments and Activity Limitations

\begin{tabular}{|c|c|c|c|c|c|c|c|c|}
\hline \multirow[b]{3}{*}{ Impairment } & \multicolumn{4}{|c|}{ Dominant Side Involvement $(n=15)$} & \multicolumn{4}{|c|}{ Nondominant Side Involvement ( $n=15)$} \\
\hline & \multicolumn{2}{|c|}{ Proportion Sitting } & \multicolumn{2}{|c|}{ Proportion Standing } & \multicolumn{2}{|c|}{ Proportion Sitting } & \multicolumn{2}{|c|}{ Proportion Standing } \\
\hline & $\beta$ & Adj $R^{2}$ & $\beta$ & Adj $R^{2}$ & $\beta$ & Adj $R^{2}$ & $\beta$ & $\operatorname{Adj} R^{2}$ \\
\hline \multicolumn{9}{|l|}{ Simple models } \\
\hline ISS-VAS & & .13 & & .02 & & .08 & & .00 \\
\hline ISS-MPQ & & .00 & & .00 & & .00 & & .00 \\
\hline ISS-AROM & & $.38^{\dagger}$ & & $.39^{+}$ & & .08 & & $.29 *$ \\
\hline ISS volume & & .07 & & .08 & & .00 & & .00 \\
\hline ISS temperature & & .00 & & .00 & & .06 & & .14 \\
\hline Strength & & $.45^{\dagger}$ & & $.26^{*}$ & & $.31 *$ & & $.35^{*}$ \\
\hline TIS & & $.21^{*}$ & & .14 & & $.46^{\dagger}$ & & $.38^{\dagger}$ \\
\hline \multicolumn{9}{|l|}{ Multiple models } \\
\hline Age & .41 & & .36 & & .28 & & .14 & \\
\hline ISS-AROM & -.31 & & -.57 & & - & & -.37 & \\
\hline Strength & -.30 & & -.01 & & -.56 & & -.42 & \\
\hline Total adjusted $R^{2}$ & & $.57^{\dagger}$ & & $.43^{*}$ & & $.34 *$ & & $.37^{*}$ \\
\hline
\end{tabular}

NOTE. Proportion are dependent variables and impairment outcome measures are independent variables, for both subgroups separately. For the simple models, the adjusted $R^{2}$ is shown. For the multiple models, the standardized $\beta$ regression coefficients and the total adjusted $R^{2}$ are shown for impairments that were significant in the simple regression models (and age). Negative values were not significant in the simple model and are therefore not included in the multiple model.

${ }^{*} P \leq .05 ;{ }^{\dagger} P \leq .01$. 
impact on normal daily life of CRPS type I in the dominant side is larger than when the nondominant side is involved. This is in accordance with earlier findings and supports the intuitive idea that a dominant upper-limb involvement generally has greater impact than nondominant involvement. Subjects with dominant side involvement who were classified as limited showed a clearly decreased percentage of activity of the involved dominant side during sitting and a clearly increased percentage of activity of the noninvolved (nondominant) side during standing. It may be relatively easier to activate the noninvolved (nondominant) upper limb to compensate for decreased activity of the involved limb during standing in order to do what one wants to do. However, because upper-limb activity during sitting requires more precision skills (fine motor skills, manipulative upper limb usage), ${ }^{32}$ compensating decreased activity of the involved limb with the noninvolved (nondominant) limb may be more difficult during sitting. It was difficult to compare our findings with other studies that reported limitations in $77 \%,{ }^{24} 62 \%,{ }^{16}$ and $78 \%{ }^{20}$ of their subjects with chronic CRPS type I because the ULAM measurement technique we used was not used in these other studies.

\section{Relation Between Impairments and Limitations}

Impaired AROM and grip strength and, to a lesser extent, pain resulting from effort were the most important factors explaining variance in activity limitations in normal daily life in chronic upper-limb CRPS type I. The fact that the TIS was significant in each simple regression model underlines the fact that heterogeneous presence of impairments is a complicating factor when studying the relation between impairment and activity limitation in CRPS type I. ${ }^{11}$ In our opinion, however, it would have been inadequate to take only 1 or a few impairments into account.

In studies by Geertzen et al, ${ }^{16,25}$ a VAS for perceived activity limitations (VAS-ADLs) and 2 subscores of the GARS, ADLs and instrumental activities of daily life were used as outcome measures for activity limitations. Pain appeared to be the most important impairment limiting activity. ${ }^{16,25}$ This finding is in contrast to the present findings and could be due to different operationalization of pain degree.

One may hypothesize that the ULAM is inherently more related to motor impairments because it measures only activity limitations and not other limitations (eg, situation or communication limitations), thereby being more associated with pain resulting from effort (activity) than with momentary pain. However, the items assessed with the GARS and VAS-ADLs were also solely activity limitations. Therefore, we considered it unlikely that different operationalizations explain why pain was less important than motor impairments. Moreover, because our data on momentary pain did not differ from that of Geertzen (range, $0-80 \mathrm{~mm}$; mean, 12mm), we think this excludes volunteer and selection bias with respect to pain. The different results for pain might have been due to the different characteristics of the instruments used to determine activity limitations: the ULAM is a nonretrospective, objective outcome measure that quantifies what subjects actually do; it did not quantify perceived or self-reported limitations as do the VASADLs and GARS.

The importance of motor impairments in chronic CRPS type I has been stressed by Geertzen and others. 11,16,19,25 Clinically, this may indicate that increasing AROM and grip strength as early as possible is as (or even more) important than pain management in preventing or reducing CRPS type I-related complaints. Our aim was to find out which impairment(s) was most prominent and least variable among 30 subjects with chronic upper-limb CRPS type I and which impairment(s) explained most of the variability at the ICF activity level. It appeared that motor and sensory impairments were most prominent and equally variable. However, impaired AROM and grip strength clearly explained a higher percentage of the variability in activity limitations.

We concluded that the more impaired a subject was, the more activity limitations were present. However, caution is needed when relating quantified impairment to quantified activity limitations. ${ }^{86}$ The present cross-sectional study does not allow us to conclude that an impairment always leads to activity limitations; linear regression analysis does not address causality between variables. For example, it cannot be said that the percentage of activity was less because a hand was colder or that because of a lower activity percentage a hand becomes colder. This may also partly explain why the relations between the ICF consequences of a disease are often ambiguous. ${ }^{16,86,87}$ Our intention was to determine which impairment(s) explained most of the variability in activity limitations.

\section{Other Variables}

No relationship existed between the duration of CRPS type I and either of the outcome measures. This finding was probably due to large intersubject variability in the presence and severeness of impairments and activity limitations. Age was always included in the regression models, although it was not always significantly related to the activity-limitation outcome measures. The present subjects were representative of the CRPS type I population with respect to age. 13,16,24 Although CRPS type I predominantly affects women, ${ }^{13}$ men were clearly underrepresented in the present study. This homogeneity with respect to gender should be taken into account when findings are extrapolated to men with CRPS type I. The present study clearly shows the important influence of the involved side (dominant, nondominant) on the degree of activity limitations.

Similar to Geertzen, ${ }^{16}$ we found no evidence that early diagnosis and subsequently early initiation of therapy gives better long-term outcome. ${ }^{88}$ Causative event, employment status, marital status, and level of education were unrelated to any of the upper-limb activity outcome measures; this may be due to the relatively small number of subjects or possible selection bias. Finally, it cannot be excluded that factors other than those examined in the present study need consideration. Other impairments such as hyperhydrosis, discoloration, dystonia, tremor, or psychosocial factors such as motivation, kinesiophobia, or presence of social life events may also explain some of the variance in the activity-limitation outcome measures, but these factor were not assessed in the present study.

\section{Practical and Methodologic Issues}

Our aim was to use outcome measures that were workable and allowed quantification. The outcome measures also had to be - as far as possible - objective, reliable, and valid in order to factually describe the impairment-activity limitation relationship. A potential limitation of this study, however, was its cross-sectional nature. Because CRPS type I is a chronic disease with exacerbations and remissions even throughout the same day, ${ }^{11}$ its variability may hamper reliable measurement of some of the outcome measures. Despite this challenge the ULAM outcome measures were relatively comprehensive. Although the cohort's small resulted in a potential lack of explanatory power and biologic variance in daily activity, the explained variances in the multiple models were not low. Linear regression was used because there was no colinearity between impairment variables. Because of the subject-to-variable ratio, no independent variables other than impairment and age were included in the multiple models. 
With a device like the ULAM, activity limitations of subjects with an upper-limb disorder can be viewed from a novel perspective. The additional value of the ULAM is that it allows objective and ambulatory determination of (in-)activity of both upper limbs while a subject is performing specific mobilityrelated activities. This technique also enables differentiation between the impact of dominant side or nondominant side involvement on activity during normal daily life, a topic that has not previously been investigated. Of course, the new technique also has some disadvantages. ${ }^{57}$ The recorder and sensor could be smaller and lighter, little is known about between-day variability in activity patterns of subjects, and fitting the ULAM at home to reduce interference with normal life is time-consuming. In addition, manipulative or fine upper-limb activity, holding of objects, and leaning are currently not $100 \%$ well detected with the ULAM. ${ }^{32}$ Because many persons with upper limb CRPS type I also experience problems with these actions, in addition to decreased gross motor activity, the explained variances from the regression models probably would have been higher had we been able to accurately detect all forms of upper-limb usage. Fortunately, developing instruments, such as the ULAM, is an ongoing process of extending possibilities and optimizing current properties.

\section{CONCLUSIONS}

Thirty subjects with chronic upper limb CRPS type I showed large variability in the magnitude of their impairments. All subjects were impaired to some degree, but AROM, strength, and pain were far more severe than impaired volume or temperature. Subjects with dominant and nondominant side involvement were equally impaired, and both subgroups were also comparable with respect to other relevant variables. With respect to activity limitations, the involved upper limbs were all less active for the mean intensity and percentage of upperlimb activity; the subjects clearly spared or protected their involved side during normal daily life. This impact of upperlimb CRPS type I was more obvious during sitting than during standing. As measured with the ULAM, subjects with dominant side involvement had more activity limitations than subjects with nondominant side involvement.

Analysis of the relation between impairment and activity limitation showed that impairments associated with upper-limb CRPS type I are not related to the percentage of dynamic mobility-related activities performed. However, impaired $\mathrm{AROM}$ and grip strength and, to a lesser extent, pain resulting from effort were the most important factors explaining variance in activity limitations in normal daily life in our sample base. The more impaired a subject was, the more activity limitations were present.

Acknowledgments: We thank Bob van Hilten, Department of Neurology, LUMC, Leiden, the Netherlands, and John Krijnen, Pain Clinic, Department of Anesthesiology, Ikazia Hospital, Rotterdam, the Netherlands, for their help in recruiting the subjects, and we thank Margreet Oerlemans, Department of Allied Health Services, University Hospital Nijmegen, the Netherlands, for information related to the ISS.

\section{References}

1. Manning DC. Reflex sympathetic dystrophy, sympathetically maintained pain, and complex regional pain syndrome: diagnoses of inclusion, exclusion, or confusion? J Hand Ther 2000;13:260-8.

2. Stanton-Hicks M. Reflex sympathetic dystrophy: a sympathetically mediated pain syndrome or not? Curr Rev Pain 2000;4:26875 .

3. Bruehl S, Harden RN, Galer BS, et al. External validation of IASP diagnostic criteria for Complex Regional Pain syndrome and proposed research diagnostic criteria. International Association for the Study of Pain. Pain 1999;81:147-54.

4. Harden RN, Bruehl S, Galer BS, et al. Complex regional pain syndrome: are the IASP diagnostic criteria valid and sufficiently comprehensive? Pain 1999;83:211-9.

5. Fournier RS, Holder LE. Reflex sympathetic dystrophy: diagnostic controversies. Semin Nucl Med 1998;28:116-23.

6. Galer BS, Bruehl S, Harden RN. IASP diagnostic criteria for complex regional pain syndrome: a preliminary empirical validation study. International Association for the Study of Pain. Clin J Pain 1998;14:48-54.

7. Monti DA, Herring CL, Schwartzman RJ, Marchese M. Personality assessment of patients with complex regional pain syndrome type I. Clin J Pain 1998;14:295-302.

8. Schwartzman RJ, Kerrigan J. The movement disorder of reflex sympathetic dystrophy. Neurology 1990;40:57-61.

9. Atkins RM, Duckworth T, Kanis JA. Algodystrophy following Colles' fracture. J Hand Surg [Br] 1989;14:161-4.

10. Schasfoort FC, Bussmann JB, Stam HJ. Outcome measures for complex regional pain syndrome type I: an overview in the context of the international classification of impairments, disabilities and handicaps. Disabil Rehabil 2000;22:387-98.

11. Oerlemans HM, Goris RJ, Oostendorp RA. Impairment level sumscore in reflex sympathetic dystrophy of one upper extremity. Arch Phys Med Rehabil 1998;79:979-90.

12. Geertzen JH. Reflex sympathetic dystrophy. Outcome and measurement studies. Introduction. Acta Orthop Scand Suppl 1998; 279:1-3.

13. Veldman PH, Reynen HM, Arntz IE, Goris RJ. Signs and symptoms of reflex sympathetic dystrophy: prospective study of 829 patients. Lancet 1993;342:1012-6.

14. Kurvers HA. Reflex sympathetic dystrophy: a clinical and experimental study. Maastricht (The Netherlands): Univ Hospital Maastricht; 1997.

15. Geertzen JH, Dijkstra PU, Groothoff JW, ten Duis HJ, Eisma WH. Reflex sympathetic dystrophy of the upper extremity-a 5.5-year follow-up. Part II. Social life events, general health and changes in occupation. Acta Orthop Scand Suppl 1998;279:19-23.

16. Geertzen JH, Dijkstra PU, Groothoff JW, ten Duis HJ, Eisma WH Reflex sympathetic dystrophy of the upper extremity-a 5.5-year follow-up. Part I. Impairments and perceived disability. Acta Orthop Scand Suppl 1998;279:12-8.

17. Borg AA. Reflex sympathetic dystrophy syndrome: diagnosis and treatment. Disabil Rehabil 1996;18:174-80.

18. Galer BS, Butler S, Jensen MP. Case reports and hypothesis: a neglect-like syndrome may be responsible for the motor disturbance in reflex sympathetic dystrophy (Complex Regional Pain Syndrome-1). J Pain Symptom Manage 1995;10:385-91.

19. Ribbers G, Geurts AC, Mulder T. The reflex sympathetic dystrophy syndrome: a review with special reference to chronic pain and motor impairments. Int J Rehabil Res 1995;18:277-95.

20. Inhofe PD, Garcia-Moral CA. Reflex sympathetic dystrophy. A review of the literature and a long-term outcome study. Orthop Rev 1994:23:655-61.

21. Field J, Warwick D, Bannister GC. Features of algodystrophy ten years after Colles' fracture. J Hand Surg [Br] 1992;17:318-20.

22. Goris RJ, Reynen JA, Veldman P. [The clinical symptoms in post-traumatic dystrophy] [Dutch]. Ned Tijdschr Geneeskd 1990; 134:2138-41.

23. Poplawski ZJ, Wiley AM, Murray JF. Post-traumatic dystrophy of the extremities. J Bone Joint Surg Am 1983;65:642-55.

24. Subbarao J, Stillwell GK. Reflex sympathetic dystrophy syndrome of the upper extremity: analysis of total outcome of management of 125 cases. Arch Phys Med Rehabil 1981;62:549-54.

25. Geertzen JH, Dijkstra PU, van Sonderen EL, Groothoff JW, ten Duis HJ, Eisma WH. Relationship between impairments, disability and handicap in reflex sympathetic dystrophy patients: a longterm follow-up study. Clin Rehabil 1998;12:402-12.

26. Kemler MA, Furnee CA. The impact of chronic pain on life in the household. J Pain Symptom Manage 2002;23:433-41.

27. Gray DB, Hendershot GE. The ICIDH-2: developments for a new era of outcomes research. Arch Phys Med Rehabil 2000;81(12 Suppl 2):S10-4. 
28. Halbertsma J, Heerkens YF, Hirs WM, de Kleijn-de Vrankrijker MW, Dorine Van Ravensberg CD, Napel HT. Towards a new ICIDH. International Classification of Impairments, Disabilities and Handicaps. Disabil Rehabil 2000;22:144-56.

29. Simeonsson RJ, Lollar D, Hollowell J, Adams M. Revision of the International Classification of Impairments, Disabilities, and Handicaps: developmental issues. J Clin Epidemiol 2000;53:11324.

30. World Health Organization. International classification of impairments, disabilities, and handicaps. Geneva: WHO; 1980.

31. Oerlemans HM, Cup EH, DeBoo T, Goris RJ, Oostendorp RA. The Radboud skills questionnaire: construction and reliability in patients with reflex sympathetic dystrophy of one upper extremity. Disabil Rehabil 2000;22:233-45.

32. Schasfoort FC, Bussmann JB, Stam HJ. Ambulatory measurement of upper limb usage and mobility-related activities during normal daily life with an upper limb-activity monitor: a feasibility study. Med Biol Eng Comput 2002;40:173-82.

33. Schasfoort FC, Bussmann JB, Zandbergen AM, Stam HJ. Impact of upper limb complex regional pain syndrome type 1 on everyday life measured with a novel upper limb-activity monitor. Pain 2003;101:79-88

34. Stanton-Hicks M, Janig W, Hassenbusch S, Haddox JD, Boas R, Wilson P. Reflex sympathetic dystrophy: changing concepts and taxonomy. Pain 1995;63:127-33.

35. Zuurmond WW, Langendijk PN, Bezemer PD, Brink HE, de Lange JJ, van Loenen AC. Treatment of acute reflex sympathetic dystrophy with DMSO 50\% in a fatty cream. Acta Anaesthesiol Scand 1996;40:364-7.

36. Braus DF, Krauss JK, Strobel J. The shoulder-hand syndrome after stroke: a prospective clinical trial. Ann Neurol 1994;36:72833.

37. Geertzen JH, de Bruijn H, de Bruijn-Kofman AT, Arendzen JH. Reflex sympathetic dystrophy: early treatment and psychological aspects. Arch Phys Med Rehabil 1994;75:442-6.

38. Deuschl G, Blumberg H, Lucking $\mathrm{CH}$. Tremor in reflex sympathetic dystrophy. Arch Neurol 1991;48:1247-52.

39. van Hilten JJ, van de Beek WJ, Vein AA, van Dijk JG, Middelkoop HA. Clinical aspects of multifocal or generalized tonic dystonia in reflex sympathetic dystrophy. Neurology 2001;56: $1762-5$.

40. Marsden CD, Obeso JA, Traub MM, Rothwell JC, Kranz H, La Cruz F. Muscle spasms associated with Sudeck's atrophy after injury. BMJ 1984;288:173-6.

41. Verdugo RJ, Ochoa JL. Abnormal movements in complex regional pain syndrome: assessment of their nature. Muscle Nerve 2000;23:198-205.

42. van Hilten BJ, van de Beek WJ, Hoff JI, Voormolen JH, Delhaas EM. Intrathecal baclofen for the treatment of dystonia in patients with reflex sympathetic dystrophy. N Engl J Med 2000;343:62530.

43. Oerlemans HM, Graff MJ, Dijkstra-Hekkink JB, de Boo T, Goris RJ, Oostendorp RA. Reliability and normal values for measuring the skin temperature of the hand with an infrared tympanic thermometer: a pilot study. J Hand Ther 1999;12:284-90.

44. Carlsson AM. Assessment of chronic pain. I. Aspects of the reliability and validity of the visual analogue scale. Pain 1983;16: 87-101.

45. Davidoff G, Morey K, Amann M, Stamps J. Pain measurement in reflex sympathetic dystrophy syndrome. Pain 1988;32:27-34.

46. Rauck RL, Eisenach JC, Jackson K, Young LD, Southern J. Epidural clonidine treatment for refractory reflex sympathetic dystrophy. Anesthesiology 1993;79:1163-9; discussion 27A.

47. Ramamurthy S, Hoffman J. Intravenous regional guanethidine in the treatment of reflex sympathetic dystrophy/causalgia: a randomized, double-blind study. Guanethidine Study Group. Anesth Analg 1995;81:718-23.

48. van der Kloot WA, Oostendorp RA, van der Meij J, van den Heuvel J. [The Dutch version of the McGill pain questionnaire: a reliable pain questionnaire] [Dutch]. Ned Tijdschr Geneeskd 1995; 139:669-73.

49. Geertzen JH, Dijkstra PU, Stewart RE, Groothoff JW, Ten Duis HJ, Eisma WH. Variation in measurements of range of motion: a study in reflex sympathetic dystrophy patients. Clin Rehabil 1998; 12:254-64

50. Adams LS, Green LW, Topoozian E. Range of motion. In: Casanova J, editor. Clinical assessment recommendations. Vol 2. Chicago: American Society of Hand Therapists; 1992. p 55-70.

51. Geertzen JH, Dijkstra PU, Stewart RE, Groothoff JW, ten Duis HJ, Eisma WH. Variation in measurements of grip strength. A study in reflex sympathetic dystrophy patients. Acta Orthop Scand Suppl 1998;279:4-11

52. Tulen JH, Bussmann HB, van Steenis HG, Pepplinkhuizen L, Man in 't Veld AJ. A novel tool to quantify physical activities: ambulatory accelerometry in psychopharmacology. J Clin Psychopharmacol 1997; 17:202-7.

53. Bussmann HB, Reuvekamp PJ, Veltink PH, Martens WL, Stam HJ. Validity and reliability of measurements obtained with an "activity monitor" in people with and without a transtibial amputation. Phys Ther 1998;78:989-98.

54. Bussmann JB, van de Laar YM, Neeleman MP, Stam HJ. Ambulatory accelerometry to quantify motor behaviour in patients after failed back surgery: a validation study. Pain 1998;74:153-61.

55. Bussmann JB, Tulen JH, van Herel EC, Stam HJ. Quantification of physical activities by means of ambulatory accelerometry: a validation study. Psychophysiology 1998;35:488-96.

56. Van den Berg-Emons HJ, Bussmann JB, Balk AH, Stam HJ. Validity of ambulatory accelerometry to quantify physical activity in heart failure. Scand J Rehabil Med 2000;32:187-92.

57. Bussmann JB, Martens WL, Tulen JH, Schasfoort FC, van den Berg-Emons HJ, Stam HJ. Measuring daily behaviour using ambulatory accelerometry: the Activity Monitor. Behav Res Methods Instrum Comput 2001;33:349-56.

58. Renfrew JW, Moore AM, Grady C, et al. A method for measuring arm movements in man under ambulatory conditions. Ergonomics 1984;27:651-61.

59. Renfrew JW, Pettigrew KD, Rapoport SI. Motor activity and sleep duration as a function of age in healthy men. Physiol Behav 1987:41:627-34.

60. Patterson SM, Krantz DS, Montgomery LC, Deuster PA, Hedges SM, Nebel LE. Automated physical activity monitoring: validation and comparison with physiological and self-report measures. Psychophysiology 1993;30:296-305.

61. van Hilten B, Hoff JI, Middelkoop HA, et al. Sleep disruption in Parkinson's disease. Assessment by continuous activity monitoring. Arch Neurol 1994;51:922-8.

62. van Vugt JP, van Hilten BJ, Roos RA. Hypokinesia in Huntington's disease. Mov Disord 1996;11:384-8.

63. Veltink PH, Bussmann HB, de Vries W, Martens WL, Van Lummel RC. Detection of static and dynamic activities using uniaxial accelerometers. IEEE Trans Rehabil Eng 1996;4:375-85.

64. Jain A, Martens WL, Mutz G, Weiss RK, Stephan E. Towards a comprehensive technology for recording and analysis of multiple physiological parameters within their behavioral and environmental context. In: Fahrenberg J, Myrtek M, editors. Ambulatory assessment; computer-assisted psychological and psychophysiological methods in monitoring and field studies. Seattle: Hogrefe \& Huber; 1996. p 215-36.

65. van den Berg-Emons HJ, Bussmann JB, Brobbel AS, Roebroeck ME, van Meeteren J, Stam HJ. Everyday physical activity in adolescents and young adults with meningomyelocele as measured with a novel activity monitor. J Pediatr 2001;139:880-6.

66. van den Berg-Emons HJ, Bussmann JB, Balk A, Keijzer-Oster D, Stam HJ. Level of activities associated with mobility during everyday life in patients with chronic congestive heart failure as measured with an "activity monitor". Phys Ther 2001;81:1502-11.

67. Jankovic J, Van der Linden C. Dystonia and tremor induced by peripheral trauma: predisposing factors. J Neurol Neurosurg Psychiatry 1988;51:1512-9.

68. Galer BS, Henderson J, Perander J, Jensen MP. Course of symptoms and quality of life measurement in Complex Regional Pain Syndrome: a pilot survey. J Pain Symptom Manage 2000;20:28692.

69. Schott GD. The relationship of peripheral trauma and pain to dystonia. J Neurol Neurosurg Psychiatry 1985;48:698-701. 
70. Bhatia KP, Bhatt MH, Marsden CD. The causalgia-dystonia syndrome. Brain 1993;116:843-51.

71. Sherman RA, Karstetter KW, Damiano M, Evans CB. Stability of temperature asymmetries in reflex sympathetic dystrophy over time and changes in pain. Clin J Pain 1994;10:71-7.

72. Awerbuch MS. Thermography-its current diagnostic status in musculoskeletal medicine. Med J Aust 1991;154:441-4.

73. Bej MD, Schwartzman RJ. Abnormalities of cutaneous blood flow regulation in patients with reflex sympathetic dystrophy as measured by laser Doppler fluxmetry. Arch Neurol 1991;48:912-5.

74. Oerlemans HM, Perez RS, Oostendorp RA, Goris RJ. Objective and subjective assessments of temperature differences between the hands in reflex sympathetic dystrophy. Clin Rehabil 1999;13: 430-8.

75. Wasner G, Schattschneider J, Heckmann K, Maier C, Baron R. Vascular abnormalities in reflex sympathetic dystrophy (CRPS I): mechanisms and diagnostic value. Brain 2001;124:587-99.

76. Bonica JJ. Causalgia and other reflex sympathetic dystrophies. Postgrad Med 1973;53:143-8.

77. Steinbrocker O. The shoulder-hand syndrome: present perspective. Arch Phys Med Rehabil 1968;49:388-95.

78. Bickerstaff DR, Kanis JA. Algodystrophy: an under-recognized complication of minor trauma. Br J Rheumatol 1994;33:240-8.

79. Zyluk A. The sequelae of reflex sympathetic dystrophy. J Hand Surg [Br] 2001;26:151-4.

80. Bruehl S, Harden RN, Galer BS, Saltz S, Backonja M, StantonHicks M. Complex regional pain syndrome: are there distinct subtypes and sequential stages of the syndrome? Pain 2002;95: $119-24$

81. Melzack R. The McGill Pain Questionnaire: major properties and scoring methods. Pain 1975;1:277-99.
82. Reading AE. A comparison of the McGill Pain Questionnaire in chronic and acute pain. Pain 1982;13:185-92.

83. Wewers ME, Lowe NK. A critical review of visual analogue scales in the measurement of clinical phenomena. Res Nurs Health 1990;13:227-36.

84. Oldfield RC. The assessment and analysis of handedness: the Edinburgh inventory. Neuropsychologia 1971;9:97-113.

85. Henkel V, Mergl R, Juckel G, et al. Assessment of handedness using a digitizing tablet: a new method. Neuropsychologia 2001 ; 39:1158-66.

86. Rondinelli RD, Dunn W, Hassanein KM, et al. A simulation of hand impairments: effects on upper extremity function and implications toward medical impairment rating and disability determination. Arch Phys Med Rehabil 1997;78:1358-63.

87. Brummel-Smith K. Research in rehabilitation. Clin Geriatr Med 1993;9:895-904

88. Baron R, Maier C. Reflex sympathetic dystrophy: skin blood flow, sympathetic vasoconstrictor reflexes and pain before and after surgical sympathectomy. Pain 1996;67:317-26.

\section{Suppliers}

a. Braun Pro 3000 type 6014; Gillette Gruppe Deutschland GmbH \& Co. oHG, Verbraucherreferat, PO Box 1150, 61466 Kronberg, Germany.

b. Volumeters Unlimited Inc, 4371 E St John Rd, Phoenix, AZ 85032.

c. Microfet, Force Evaluating and Testing System; Hoggan Health Industries Inc, 12411 S 265 W, Draper, UT 84020.

d. ADXL 202 (size, $1 \times 1 \times 0.5 \mathrm{~cm}$ ); Analog Devices Inc, One Technology Way, PO Box 9106, Norwood, MA 02062-9106.

e. TEMEC Instruments BV, Spekhofstraat 2, NL-6466 LZ Kerkrade, The Netherlands.

f. SanDisk Corp, 140 Caspian Ct, Sunnyvale, CA 94089

g. SPSS Inc, $233 \mathrm{~S}$ Wacker Dr, 11th Fl, Chicago, IL 60611. 